\section{O JUSTIÇAMENTO COLETIVO E A VIOLAÇÃO DOS DIREITOS HUMANOS NO ESTADO DEMOCRÁTICO DE DIREITOS}

\author{
Carolina Carreiro Alencar de Carvalho
}

\author{
Bacharel em Ciência Política - Universidade \\ Federal do Piauí
}

\begin{abstract}
Resumo: Com a iminência da derrocada do Estado Democrático de Direito, a sociedade debilita-se e os órgãos do Estado mostram-se de todo incompetentes no exercício de suas funções mais elementares; Educação, Trabalho e Segurança. Compreendendo este contexto, o artigo propõe relacionar as ondas de Justiçamento Coletivo que vem acontecendo na sociedade brasileira, como reflexo do divórcio entre estado e sociedade. Expressando uma crise de desagregação social, onde a sociedade civil apresenta alternativas desordenadas de reestabelecimento da ordem, rompidas por modalidades socialmente corrosivas de conduta social. Usando como aporte teórico a categoria da Banalidade do Mal, de Hannah Arendt, analisam-se os padrões de Legitimação de Extermínio provenientes do social em vigor, que possibilitam a sociedade civil protagonizar as maiores atrocidades. A metodologia para a constituição do artigo será dividia em dois momentos; Pesquisa Bibliográfica e Pesquisa Documental.
\end{abstract}

Palavras - Chaves: Estado de Direitos, Legitimação de Extermínio, Ética do Pensar.

Abstract: With the imminent collapse of the rule of democratic state, society, and weakens the organs of state show up at all incompetent in performing their most basic functions; Education, Labor and Security. Understanding this context, the paper proposes to relate the waves of 'justice Collective that has been going in Brazilian society, reflecting the divorce between state and society. Expressing a crisis of social breakdown, where civil society has disordered alternative reestablishment of order, disrupted by socially corrosive forms of social conduct. Using as theoretical support the category the Banality of Evil, Hannah Arendt, analyze Extermination Legitimacy of the standards from the social in place that enable civil society protagonists the greatest atrocities. The method for forming the article will be divided into two stages; Bibliographical Research and Research Document.

Keywords: State of Rights, Legitimacy of Extermination, the Think Ethics.

A Luz do Público Obscurece Tudo.

(Hannah Arendt)

Com a Declaração Universal dos direitos humanos, acreditou-se que pela primeira vez um sistema de princípios fundamentais da conduta humana foi livre e expressamente aceito, através de seus respectivos governos, por uma ampla maioria no ocidente. Para Bobbio, com ela foi possível ter a certeza histórica de que a humanidade, em sua grande maioria, partilha de alguns valores comuns, e que poderia finalmente crer na universalidade desses valores. No entanto o processo de universalização desses direitos passa por uma série de dificuldades, causadas tanto por problemas inerentes aos fundamentos e à fragilidade da garantia e proteção destes direitos dentro e fora dos Estados Nação. A Declaração proclama princípios não como normas jurídicas, mas como "ideal comum a ser alcançado por todos os povos e por todas as nações". Alguns países fazem com que as normas jurídicas sejam influenciadas por estes princípios, mas estão contidos em um juízo hipotético. Quando os direitos do homem eram considerados unicamente como direitos naturais, a única defesa possível contra a sua violação pelo Estado era um direito igualmente natural, o chamado direito de resistência. Mais tarde nas Constituições que reconheceram a proteção jurídica de alguns desses direitos, o direito natural de resistência transformou-se no direito positivo de promover uma ação judicial contra os próprios órgãos do Estado. Porém o que podem fazer os cidadãos de um Estado que não tenham reconhecido os direitos do homem 
como direitos dignos de proteção? E o que podem fazer os cidadãos que não pertencem a um Estado Nação? (BOBBIO, 1992, P. 31).

Para Hannah Arendt, a Declaração dos Direitos do Homem significou o prenúncio da emancipação do homem, porque foi a partir daquele momento que ele se tornou a fonte de toda a lei. $\mathrm{O}$ homem não estaria mais sujeito a regras provindas de uma entidade divina ou assegurada meramente pelos costumes da história, mas havia se libertado de qualquer tutela e que era dotado de direitos simplesmente porque são Homens. No entanto para que valores universais sejam constituídos, não se leva em consideração a condição humana da pluralidade, essencial a ação e a dignidade humana. Para Arendt, essa contradição entre os direitos humanos conforme pensados desde o século XVIII e a condição humana da pluralidade, e consequentemente, contradição com a dignidade humana, fica aparente no caso de pessoas excluídas de comunidades, como é o caso dos apátridas e das minorias étnicas vivendo sob um Estado Nação de uma etnia diferente. E para além dos problemas de fundamentação, determinadas comunidades, apesar de adotarem em suas constituições Direitos Fundamentais, apresentam grandes dificuldades em garantir tais direitos. As Sociedades modernas são marcadas por uma forma de igualdade que é juridicamente delimitada, como é o exemplo do processo de construção dos Estados de Direitos, em suma, é a igualdade de direitos de todos os cidadãos pertencentes a um Estado Nacional, mas quando ultrapassamos este plano e nos voltamos para a dimensão social da vida coletiva esta igualdade de direito encontra-se ameaçada pela desigualdade do sistema econômico, esta desigualdade de condições econômicas resulta em desigualdades socais mais amplas, que apresentam consequências para além da dificuldade de acesso a direitos fundamentais. (MARTINS, 2014, P. 163).

A igualdade é uma construção que se dá nos embates sociais, produto e expressão da superação dos bloqueios a que a igualdade se confirme. A construção da igualdade se dá no campo de possibilidades e de limitações. É evidente que não basta à lei dizer que somos iguais. No Brasil, a igualdade social e de direitos foi politicamente proposta, justamente pelos beneficiários da desigualdade e proposta, portanto, como igualdade limitada e condicional. Se a igualdade é uma construção social e política, a diferença na igualdade também o é. As diferenças de acesso que hoje geram a destituição da possibilidade de inserção na modernidade social, de determinadas categorias como os marginalizados, pobres, negros, entre outros, é resultante das iniquidades sociais herdadas da sociedade colonial. O que dificulta a aceitação de uma sociedade na sua universalidade, refreando a consciência social que pense a redução de determinadas discriminações. (MARTINS, 2014, P. 163, 167). Para compreender melhor o problema de acesso aos direitos fundamentais no país é necessário apontar determinados fatos.

Com o surgimento da terceira onda democrática no Brasil, o retorno à democracia foi acompanhado da remoção do chamado "entulho autoritário", com o propósito de retirar todos os obstáculos institucionais, principalmente legais, que haviam limitado as liberdades civis e públicas. Tratava-se de restituir à sociedade brasileira os direitos e garantias que caracterizavam sociedades livres, pluralistas e democráticas. As principais reivindicações giravam em torno de questões como eleições livres, universais e sujeitas às regras da competição política, a garantia das demais liberdades- de pensamento, opinião, crenças políticas e religiosas, de organização e de associação, o que necessariamente se 
traduzia em interdição constitucional à censura, aos órgãos de formação de opinião, às artes em geral, bem como interdição às práticas de perseguição às dissidências políticas. No entanto, as lideranças políticas que haviam lutado pelo retorno do país à normalidade democrática se deram conta que, para além da reconstrução de tal normalidade, era fundamental ampliar os espaços de participação e de representação política, o que se traduzia em maior proximidade entre governantes e governados, maior presença das instituições de justiça na vida dos cidadãos comuns, como também maiores possibilidades de interlocução entre classe política, partidos, movimentos e associações civis na formulação e execução de políticas públicas, consideradas essenciais para redução das desigualdades sociais e promoção do bem-estar. (SINHORETO, 2011).

No bojo deste movimento da sociedade em direção à consolidação da democracia no Brasil se apresenta o tema clássico o do acesso à justiça. É certo que desde os primórdios da República, intelectuais e especialistas criticavam os estreitos caminhos institucionais facultados aos cidadãos comuns para a defesa de seus interesses ou mesmo para a solução de conflitos de diversas ordens em suas relações civis e com os poderes constituídos. Era forte o sentimento de que as instituições promotoras de justiça estavam a serviço dos interesses das elites proprietárias e políticas, pouco restando aos cidadãos procedentes das classes trabalhadoras de baixa renda senão se resignar diante do poder dos poderosos. Para Sinhoretto, entre o povo e a justiça pública persistiam abismos quase intransponíveis. A maior presença dessas instituições na vida das classes trabalhadoras se fazia através de suas funções de controle social e a repressão da ordem pública. Ainda assim, não estavam de fato garantidos os direitos de acesso universal à justiça e de ampla defesa aos acusados de crime, procedentes das assim chamadas "classes perigosas", senso comum recorrente tanto na imprensa daquela época quanto em parcelas da opinião pública para criminalizar o comportamento dos pobres. $\mathrm{Na}$ sociedade civil brasileira, as comunidades das periferias apresentam uma enorme dificuldade de acesso a seus direitos, como consequência da dificuldade de acesso ao sistema legal de Justiça. A periferia e a pobreza aparecem como uma geográfica a parte, onde a distância, a diferenciação da paisagem e a diferenciação social constituam limites não só de fato, mas de direito, à ação da polícia e do Judiciário nesses lugares distantes. Existe, portanto certa aceitação da incapacidade do poder público em oferecer segurança nos bairros da periferia e em zonas periféricas. A falta de policiamento não é vista como irresponsabilidade de uma política pública de segurança e justiça ineficaz e ultrapassada, que deveria ser exercida igualmente em todos os lugares. (SINHORETTO, 2011).

Com o retorno ao estado de direito o tema da reforma da justiça entrou em destaque em especial em meados dos anos 90 do século passado com o crescimento dos crimes e da violência, tendo forte impacto na opinião pública e na disseminação de sentimentos coletivos de insegurança. Consequências do envelhecimento das leis penais, da estrutura e organização do sistema de justiça criminal, dos processos de formação e recrutamento de operadores técnicos e não técnicos para as funções do controle legal dos crimes. Tais problemas foram agravados pelo descaso com que por anos a fio as autoridades governamentais trataram problemas de segurança pública, foi frequentemente responsabilizado em grande medida pelos problemas experimentados neste domínio da vida coletiva. Os sentimentos de medo e insegurança estão lastrados em fatos, apontando o crescimento dos homicídios e dos crimes contra patrimônio, além da disseminação 
nos bairros populares de esquadrões de morte, justiceiros além de casos de linchamentos. (SINHORETTO, 2011).

Compreendendo o processo de redemocratização e acesso aos direitos no Brasil, busca-se analisar os linchamentos como o resultado de ações coletivas que fazem parte de um universo cultural, sendo resultantes de operações de sentido, de uma racionalidade, de uma intenção, de uma mensagem. Fora da discussão que classifica os Justiçamentos Coletivos como ações irracionais e de barbárie, classificando-os no domínio do instintivo e do inumano. Mas como uma ação que faz parte de uma demora cultural na mentalidade que permanece, ainda que impregnada de disfarces de uma atualidade que não é a do novo, mas a do persistente. Trágica expressão do divórcio entre o legal e o real que historicamente preside nos impasses da sociedade brasileira, divórcio entre o poder e o povo, entre o Estado e a Sociedade. Os linchamentos, de certo modo, são manifestações de agravamento dessa tensão constitutiva do que somos. Crescem numericamente quando aumenta a insegurança em relação à proteção que a sociedade deve receber do Estado, quando as instituições não se mostram eficazes no cumprimento de suas funções, quando há medo em relação ao que a sociedade é e ao lugar que cada um nela ocupa.

\section{A Burocratização e o Estado de Direitos}

As transformações globais da esfera econômica, trazidas pelo declínio do modelo do Estado Providência e sua substituição por formas estatais marcadas pelas reformas de cunho neoliberal, com objetivo de reduzir a participação do Estado como agente econômico, desregulamentando a economia. O modelo do bem-estar estava assentado no compromisso fordista, que estabelecia um padrão para as lutas sociais e para a participação das classes populares na redistribuição da riqueza. Seu declínio intensificou a expressão dos conflitos por novas vias e canais de resolução, incrementando o apelo à via judicial. Coincidentemente ao aumento de demanda para garantia judicial de direitos sociais ameaçados pelas reformas, um novo processo de codificação de direitos surgia, provocado pela emergência de novos sujeitos sociais protagonizando novos conflitos: de gênero, ambientais, de defesa de minorias étnicas e culturais. Tão importantes para as transformações jurídicas da contemporaneidade, quanto aquelas ocorridas na esfera econômica e na esfera das nações, as transformações culturais que reorganizaram a família, o trabalho feminino, a ecologia, as políticas do corpo, as relações com as diferenças sexuais, religiosas, raciais, afetaram o cotidiano de todas as classes, em praticamente todos os países do mundo. Antes de tudo, iniciava-se um questionamento do estatuto da igualdade formal diante das desigualdades de fato, abrindo a crítica do tratamento desigual da lei às demandas dos diferentes segmentos. Essas transformações, que redefiniram a micropolítica do cotidiano, também impactaram o sistema judicial na medida em que invocaram novos direitos, os quais trouxeram uma inovação, por não serem postulados e tutelados individualmente, requerendo a criação de institutos processuais inéditos como as ações judiciais coletivas. (SINHORETTO, 2011).

Ao crescimento da demanda por tutela judicial motivado, de um lado, pelo declínio do Estado de Bem-estar social e, de outro, pelo surgimento dos "novos direitos" designa-se explosão de litigiosidade, isto é, uma requalificação da busca dos tribunais para a garantia de direitos já efetivados (e atualmente ameaçados) e para a efetivação de direitos recémconquistados e ainda não institucionalizados. Portanto, a atuação do Judiciário começou a transcender o modelo do juiz como mero aplicador de lei, consagrado no sistema de civil 
law adotado pelos países da Europa continental e suas ex-colônias. $\mathrm{O}$ fenômeno do novo constitucionalismo, típico da construção formal das democracias erigidas no pós-guerra, representa a preocupação em codificar e garantir a efetividade de direitos fundamentais nas diversas esferas da vida social, introduzindo, com isso, princípios de justiça social na aplicação do direito. $\mathrm{O}$ judiciário passou a ser um ator relevante no processo de efetivação dos direitos sociais, incorporando um sentido prospectivo nas suas decisões. Dito de outra forma, passou a partilhar da formulação de políticas públicas ao lado do Executivo e do Legislativo. A atividade de interpretação das normas tornou-se, com o constitucionalismo democrático, muito mais complexo por envolver, além da coerência interna das normas, a realização de princípios defendidos na Constituição, mas ainda não institucionalizados. Com o declínio do modelo estatal do bem-estar, o controle constitucional dos atos de governo se tornou cada vez mais uma atividade política: na medida em que a política convencional se enfraquecia como arena de expansão dos direitos sociais, politizava-se a atividade jurisdicional, buscada como alternativa de realização desses direitos. A esse processo de "desneutralização" e politização da atividade jurisdicional se deu o nome de Judicialização da política. Isto é, a Judicialização da política significa que a interpretação e aplicação das leis passam a ser criativa, conferindo ao Judiciário poderes legislativos e de implementação de políticas públicas classicamente prerrogativas dos poderes executivos. O processo de Judicialização da política não é uniforme, linear ou homogêneo para todos os países. No Brasil só passou a fazer sentido no processo de democratização. (SINHORETTO, 2002).

A constituição de um Poder Judiciário independente, de um direito estatal positivo, operado por um corpo de especialistas, que criam e manipulam o saber jurídico é um dos elementos fundamentais da consolidação do Estado moderno. Sua legitimidade está assentada sobre o exercício do poder regulado por normas legais, inclusive no que tange ao uso da violência, considerada legítima quando aplicada em condições autorizadas pela lei. A consolidação do direito estatal significou um marco político e cultural nas sociedades ocidentais, tornando-se o modo dominante de resolução de conflitos, todavia, outras fontes de direito informal e outros canais de resolução de controvérsias não desapareceram e, ainda que não reconhecidos pelo Estado, são praticados pelas populações. O Estado nacional não detém o monopólio de produção do direito e de distribuição de justiça, situação a que se dá o nome de pluralismo jurídico. Isto é, nas sociedades contemporâneas, outras instâncias sociais produzem direitos não- oficiais e administram conflitos através de mecanismos e rituais extralegais. Se as formas alternativas são pelo menos tão antigas quanto o direito estatal, no mundo contemporâneo elas adquirem uma importância singular, por uma série de dificuldades na universalização da oferta de serviços de justiça pelo Estado. Apenas uma parte dos conflitos é absorvida e administrada pelo sistema oficial, podendo ou não se converter em litigação judicial, sobretudo em países como o Brasil, onde não são poucos os problemas de acesso da população à litigação judicial. Assim, as situações sociais não canalizadas para as vias formais de resolução tendem, em parte, a ser absorvidas por sistemas alternativos de administração de conflitos, extralegais, a serem administradas de forma privada, onde o recurso à violência ilegal, a supressão do oponente, podem ter lugar. (SINHORETTO, 2002).

Não apenas o sistema oficial coexiste com os mecanismos informais de administração de 
conflitos, como esses são preferidos pelos cidadãos, por serem mais baratos, rápidos, compreensíveis e oferecerem soluções consideradas mais adequadas às peculiaridades dos litigantes e suas expectativas de resolução. $\mathrm{Na}$ vida cotidiana, apenas quando os meios informais fracassam na dissolução da controvérsia é buscada a intervenção do sistema oficial. Há barreiras econômicas de acesso ao judiciário, devido aos elevados custos de litigação judicial, determinantes para os pobres, mas não apenas as causas de pequeno valor, mesmo envolvendo cidadãos mais abastados, acabam excluídas da proteção judicial quando a litigação se torna financeiramente desvantajosa, embora seja, de fato, a população pobre a mais prejudicada, uma vez que suas causas frequentemente são de pequenos valores. Existem ainda as barreiras sociais e culturais decorrentes da distância social existente entre os operadores jurídicos e a maioria dos cidadãos, representadas pela linguagem técnico-jurídica, por ritos e procedimentos judiciais desconhecidos do público leigo, pelo desconhecimento das leis que afeta a maioria da população e, em alguns casos, pela identificação de classe dos operadores jurídicos. As barreiras sociais e culturais tendem a ser mais relevantes quanto mais baixo é o estrato social dos litigantes. Entretanto, estar informado a respeito dos direitos e dos procedimentos judiciais ainda não garante a canalização do conflito para $o$ Poder Judiciário. Experiências negativas anteriores - um repertório social de exclusão do acesso à justiça - e concepções culturais sobre justiça social, desigualdade política e valores morais podem impactar a decisão de procurar tribunais. Distâncias territoriais também costumam significar entraves, seja em áreas rurais ou urbanas, sobretudo quando se somam a dificuldades econômicas para 0 transporte. (SINHORETTO, 2002).
Compreendendo este contexto de desigualdade de acesso ao direito à Justiça à violência cresceu à medida que ocorria a transição e consolidação do governo democrático na sociedade brasileira. Com o retorno ao Estado de direito e à normalidade democrática, esperava-se conter a violência perpetrada durante o regime autoritário contra a dissidência política e à oposição durante o regime autoritário contra a dissidência política e à oposição político-partidária. De fato, à medida em que a transição avançava, a violência política era cada vez mais publicamente condenada. Acabou, por fim, controlada salvo ocorrências esparsas aqui e acolá. Não obstante, o fim da violência política não se traduziu em controle democrático sobre a violência em geral. Cresceram os crimes, mas também se observou verdadeira explosão de conflitos na sociedade civil, envolvendo em especial policiais contra civis e civis contra civis, na origem das quais se sucederam graves violações de direitos humanos. A medida em que a Justiça oficial não se faz acessível e não se mostra eficiente para canalizar e oferecer soluções satisfatórias para os conflitos que a todo instante se produzem no cotidiano. $\mathrm{O}$ terreno da solução dos conflitos passaria então a ser ocupado por iniciativas privadas de resolução, como seriam os linchamentos e toda sorte de mortes por encomenda, crimes de mando, "limpeza social", praticadas por pistoleiros profissionais, justiceiros, grupos de extermínio, chacineiros e esquadrões da morte. (MARTINS, 2015).

Para Hannah Arendt, O crescimento da violência seria uma consequência da hipocrisia dos governantes que converteram os governados engagés em enragés. Impossibilitando a construção da convivência coletiva, que requer o acesso a um espaço público comum. Esse acesso ao espaço público- o direito de pertencer a uma comunidade política- que 
permite a construção de um mundo comum através do processo de asserção dos direitos humanos. No mundo contemporâneo continuariam a persistir situações sociais, políticas e econômicas que, mesmo depois do término dos regimes autoritários, contribuíram por tornar os homens supérfluos e sem lugar num mundo comum. Entre outras tendências, menciona a ubiguidade da pobreza e da miséria; a irrupção da violência, a limpeza étnica e os fundamentalismos excludentes e intolerantes. Fundamenta-se, assim, no pressuposto de que os seres humanos independente do que fazem ou aspiram, podem a qualquer momento ser qualificados como inimigos objetivos e encarados como supérfluos para a sociedade. Tal convicção de que seres humanos são supérfluos e descartáveis, representa uma contestação frontal a ideia do valor da pessoa humana enquanto valor-fonte da legitimidade da ordem jurídica, como formulada pela tradição, senão como verdade pelo menos; como conjectura plausível da organização da vida em sociedade. Posto pela experiência da privação da cidadania, aqueles que se viram reduzidos a "mera existência em todos os assuntos de interesse público" foram arrebatados por falta de um lugar no mundo. Para a autora, à medida que os governos apresentam uma burocracia plenamente desenvolvida, maior é a burocratização da vida pública, maior será a atração pela violência. Em uma na burocracia não há ninguém a que se possa inquirir, a quem se possam apresentar queixas, sobre quem exercer as pressões do poder. Todas as pessoas estariam privadas da liberdade política, do poder de agir, pois fariam parte do Domínio de Ninguém.

Portanto, esperar de pessoas que não têm a menor noção acerca do que é uma res pública, coisa pública, que se comportem de maneira não violenta e discutam racionalmente em questões de interesse não é realista nem razoável. A violência, sendo instrumental por natureza, é racional à medida que é eficaz em alcançar o fím que deve justificá-la. E posto que, quando agimos, nunca sabemos com certeza quais serão as consequências eventuais do que se está fazendo, a violência só pode permanecer racional se almeja objetivos de curto prazo. Muito da presente glorificação da violência é causada pela severa frustração da faculdade da ação no mundo. É simplesmente verdadeiro que ações como os Linchamentos façam "com que as pessoas sintam estar agindo em conjunto de uma maneira que só raramente podem fazer". Os processos de desintegração que se tornaram tão evidentes nos anos recentes - do declínio dos serviços públicos: escolas, polícia, correio, coleta de lixo, transporte etc; a poluição do ar e da água são os resultados automáticos das necessidades das sociedades de massa, que se tornaram incontroláveis. E ao passo que não se pode dizer com segurança onde e quando será alcançado o ponto de ruptura, podem observar quase medir, quanto o vigor e a resistência de nossas instituições são insidiosamente destruídos.

\section{O Mal e os Justiçamentos Coletivos}

A perda da legitimidade do sistema oficial de justiça como uma consequência não programada da própria lógica de funcionamento e de produção da verdade - portanto da justiça - que opõe e desqualifica os diversos componentes do sistema. Polícia, Ministério Público, advogados e juízes trabalham, nos processos, para desqualificar os discursos uns dos outros, operando suas próprias lógicas, fragmentando a produção das decisões. O objetivo de cada órgão passa a ser autorreferido, num sistema que não privilegia a criação de consensos e a negociação de situações conflitivas. O sistema de produção de justiça no Brasil se propõe a descobrir a verdade sobre os fatos, visando punir aquele que quebrou a harmonia da sociedade, 
revelando assim uma concepção de mundo maniqueísta, em que o conflito é prejudicial. Para a justiça brasileira, é preciso descobrir a verdade, para punir o culpado e restituir a sociedade do mal que lhe foi causado. Não se coloca a questão de que um conflito é uma disputa de interesses diversos e que, por vezes, a expectativa das partes é de negociação, construção de um novo arranjo de poder, e não de um jogo de soma zero. Diante disso, surge o entendimento de setores da sociedade que veem o judiciário como um reprodutor de desigualdades, um agente de determinados interesses de classe, pois ao eleger a verdade, imediatamente desqualifica e marginaliza os oponentes, por vezes legitimando por decisões judiciais o arranjo de poder que está na origem do conflito. A única forma de assegurar o funcionamento da democracia social é garantir aos cidadãos o acesso à plenitude dos seus direitos, e isso só poderia ser feito através do funcionamento de um Poder Judiciário que fosse acessível e desse tratamento igual a todos. Sendo assim, o direito igualitário de acesso à justiça é o direito que assegura o acesso a todos os demais direitos. Na sociedade brasileira, o direito de acesso à justiça não é igualitário e não tem atingido a todos.

A crítica ao sistema de justiça tornou-se ainda mais aguda com o final dos anos 1990, quando o problema do medo do crime se tornou uma questão nacional. Os pesquisadores e o senso comum disseminam a ideia de que o crescimento da violência é um reflexo do mal funcionamento da Justiça, diante destas "constatações" as posições se diferenciam em dois grandes grupos. Alguns defendem o endurecimento das leis e da atuação dos agentes de segurança e justiça. Outros defendem uma reformulação mais ampla do sistema, pois discordam da sua estruturação, ocorre ainda uma critica ao trabalho da política, do Judiciário e à situação carcerária. A partir da abertura política, com o surgimento de novos direitos, os cidadãos e as organizações intensificaram a exigência de suas garantias através de processos judiciais. Isso criou um problema estrutural para a instituição, que não conseguiu se expandir nas mesmas proporções da demanda, apesar da autonomia orçamentária que conquistou em 1988. A conflitualidade social vem se tornando mais tumultuada nos últimos anos, têm crescido as taxas de violência, a inadimplência fiscal e de contratos particulares. Porém, o número de Juízes, promotores e funcionários não tem crescido para acompanhar a maior demanda por justiça. A Justiça, ao contrário da expectativa, vem perdendo agilidade nas decisões seja por excesso de formalidades do rito, ou por desfuncionalidade do sistema. Além disso, lembram os autores, que existe algo como uma "mentalidade dos juízes", que os torna avessos ao diálogo com a sociedade, ao controle externo e pouco sensíveis às mudanças que vem ocorrendo na realidade na qual estão inseridos.

A morosidade é parte nessa crise, pois ela é vista pelos agentes da justiça como um mal necessário para assegurar as garantias de defesa e acusação. No entanto, as pesquisas recentes têm apontado para o fato de que há uma morosidade decorrente da inadequação de defesa e acusação. As causas da morosidade podem ser de dois tipos: endógenas e funcionais. As causas endógenas da morosidade da justiça são aquelas inerentes ao próprio sistema judiciário, como volume excessivo de trabalho, irracionalidade na alocação de funcionários, irracionalidade de rotinas estabelecidas e consolidadas temporalmente, ou ainda problemas decorrentes de imperícia, despreparo ou negligência por parte dos responsáveis pelo serviço. As causas de tipo funcional correspondem à morosidade gerada pelas partes em litígio no processo. Esta, em regra atende ao interesse da 
parte, que utiliza uma série de expedientes para que a instrução do processo não avance, na expectativa de que o tempo possa enfraquecer o conjunto probatório. $\mathrm{O}$ tempo médio que um processo de homicídio costuma levar aqui é ainda superior ao tempo médio que leva em Portugal, na França, na Alemanha ou na Inglaterra. Se nesses países a morosidade da justiça já é posta em questão, no Brasil torna-se um entrave efetivo para o acesso dos cidadãos ao direito de justiça. Um processo pode correr por anos a fio, possibilitando que a memória de testemunhas se esvaneça, que os réus desapareçam do controle do Judiciário, ou então fiquem presos aguardando julgamento, gerando impacto no sistema penitenciário. Toda essa demora da Justiça é muito desencorajadora para quem a ela recorre. De outra parte, as decisões demoradas soam como injustiças não apenas para as vítimas, mas também para os réus, que podem vir a ser condenados muito tempo depois do delito, quando até mesmo já podem ter reorganizado sua vida e adotado um outro estilo de conduta. (SINHORETTO, 2002).

Num contexto de crescimento das necessidades de intervenção nos conflitos, como é este pelo qual passa a sociedade brasileira, a falta de respostas ágeis por parte da Justiça tem provocado descrédito e favorecido a impunidade. A Justiça criminal acaba por ocupar um espaço de aplicação seletiva da lei, cujo efeito é produzir e reproduzir as desigualdades através das práticas judiciais. Além disso o desconhecimento da população em relação às regras da justiça que torna possível a existência e a eficácia dos mecanismos de produção e reprodução das desigualdades no interior do sistema judiciário, contribui ainda mais com este fato, a adoção de uma estética, um gosto de classe e um estilo de vida que claramente identifica os juízes e promotores com um estrato social detentor de poder, dificultando para o restante da população os identificar com a defesa de um interesse público. O próprio funcionamento do sistema de justiça produz consequências não desejadas e instaura novas desigualdades nas relações sobre as quais intervém, obtendo como resultado de sua ação a deslegitimarão diante de certos grupos. Assim, a legitimidade do sistema de justiça é objeto de permanente negociação no interior da sociedade. (SINHORETTO, 2002).

É dentro deste contexto que resoluções de conflitos extra legais se desdobram na sociedade, como os linchamentos. Os linchamentos seriam práticas coletivas de execução sumária de pessoas consideradas criminosas. Sua característica diferenciada de outros tipos de execução sumária é o seu caráter de ação única, ou seja, o grupo linchador se forma em torno de uma vítima ou grupo de vítimas, e após a ação, se dissolve. Por isso, diz-se dos linchamentos que são ações espontâneas e sem prévia organização. No entanto, isso não quer dizer que os participantes de uma ação como essa não a planejam ou não prevejam, por vezes, suas consequências. O linchamento é tratado por certos pesquisados como uma ação irracional, no entanto é considerado neste artigo a teoria de Jacqueline Sinhoretto, para qual os linchamentos seriam inscritos dentro de uma razão concorrente à racionalidade da justiça oficial. A maior parte dessas ações ocorrem em áreas de alta concentração urbana, mas uma parte representativa dos linchamentos ocorre também nas áreas rurais. Estas formas de ação violenta Geralmente são motivados pela ocorrência de um crime de sangue (um homicídio, um latrocínio, um estupro seguido de morte) ou por outros crimes contra a pessoa. Mas há também linchamentos motivados por crime de roubo, invasão de residência e até corrupção nas prefeituras. Nas periferias das grandes cidades e nas cidades pequenas predominam um tipo de ação praticada por um 
grupo de pessoas que se conhecia ao menos de vista. São moradores do próprio local que se associam com seus vizinhos para realizar ações violentas que objetivam devolver à região a ordem pública. Esse tipo de prática é mais frequentemente detonada por um crime de sangue, ao passo que os linchamentos característicos dos centros das grandes cidades, em que os participantes não se conhecem nem sequer de vista, são mais comumente motivados por um crime contra a propriedade. (SINHORETTO, 2002).

Para Jacqueline Sinhoretto, os Linchamentos ocorreriam porque existe uma desconfiança com relação à eficiência da polícia e da justiça em conter a criminalidade, seja porque a população que pratica o linchamento reivindica uma outra forma de fazer justiça. Em alguns desses casos, a população conta com o apoio das próprias autoridades públicas. Em praticamente metade dessas ações a vítima é salva pela intervenção da polícia, que resgata a vítima do linchamento e dispersa o grupo. Ocorre porém que poucos casos de linchamento são levados ao sistema de justiça para responsabilização dos linchadores por homicídio ou lesões corporais e são raríssimos os casos de julgamento ou prisão de linchadores. Duas são as explicações possíveis para a não criminalização dos linchamentos. A primeira delas, de ordem mais prática, é a de que por se tratar de uma ação coletiva, é muito mais difícil identificar os participantes e poder dar prosseguimento ao rito judicial. A outra explicação possível é a de que as autoridades públicas e a comunidade não querem ver os linchadores presos, pois enxergam a legitimidade dessas práticas.

Para José de Souza Martins, os Linchamentos fariam parte de um espaço de uma travessia inacabada, em que se aglomeram migrantes temporários e permanentes, populações bloqueadas no tempo e no espaço da porta de entrada no mundo moderno, refugos malqueridos da agricultura tradicional e rejeitos temidos da grande indústria da cidade. Os atos de linchamento, às vezes muito elaborados, revelam-se ritos de definição do estranho e da estraneidade da vítima, o recuso e o excluído. Eles denunciam o estreitamento das possibilidades de participação social daqueles que, deslocados por transformações econômicas e sociais, situam-se nas franjas da sociedade, nos lugares da mudança e da indefinição sociais. Ao mesmo tempo, denunciam a perda de legitimidade das instituições públicas, através do aparecimento de uma legitimidade alternativa, que escapa das regras do direito e da razão. Pode-se dizer que, de certo modo, o "contrato social" está sendo rompido. Nesse sentido, os linchamentos são importantes, também, do ponto de vista político.

Para José de Souza Martins, no Brasil os linchadores querem alcançar fundamentalmente a própria vítima, não havendo nítidas preocupações com transgressores potenciais. $\mathrm{O}$ objetivo não é o de prevenir o crime por meio da aterrorização, mas o de punir um crime com redobrada crueldade em relação ao delito que o motiva. Aqui o linchamento é claramente vingativo. No nosso caso, os linchamentos sugerem que há um arraigado sistema de valores subjacente ao comportamento coletivo violento. E, ao mesmo tempo, uma combinação difícil entre ele e os valores racionais da lei e da justiça. Há uma dupla moral envolvida nessas ocorrências - a popular e a legal. Os linchadores indicam que há violações insuportáveis de normas e valores, assim, o linchamento seria uma forma incipiente de participação democrática na construção (ou reconstrução) da sociedade, de proclamação e afirmação de valores sociais, incipiente e contraditória porque afirma a soberania do povo, mas nega a racionalidade impessoal da justiça e do direito. O linchamento não é uma 
manifestação da desordem, mas de questionamento da desordem, os Justiçamentos envolvem mais do que súbita e solidária decisão de matar violenta e coletivamente alguém. Há uma certa ideia de corpo, de pertencimento, envolvida na ocorrência. Os linchamentos são mais do que um problema social; são expressões trágicas de complicados processos de desagregação social e, também, de busca de um padrão de sociabilidade diferente daquele que se anuncia através das tendências sociais desagregadoras. Seria pobre a interpretação que se limitasse a vê-los como manifestação de conservadorismo ou que, ao contrário, se limitasse a neles ver indicação de uma conduta cidadã e inovadora, ainda que e equivocada na forma. Antes, é necessário neles resgatar a dimensão propriamente dramática do medo e da busca, ingredientes que muitas vezes acompanham os processos de mudança social.

Esses ingredientes ganhariam sentido na tradição conservadora relativa a certa visão de mundo centrada mais na categoria de pessoa do que na categoria de indivíduo. Tradição, por sua vez, revigorada justamente, ao que tudo indica, pela características excludentes e patológicas do nosso desenvolvimento social, em particular do desenvolvimento urbano. Tendências de desenvolvimento e subdesenvolvimento simultâneas muito polarizadas, cujos extremos estão excessivamente distantes entre si, parecem estabelecer linhas de desigualdade social que delimitam mais do que riqueza e pobreza e que acabam afetando profundamente mais do que riqueza e pobreza, acabam afetando profundamente a própria concepção de humano e pessoa. O tema do linchamento é um desses temas reveladores da realidade mais profunda de uma sociedade, de seus nexos mais ocultos e ativos. Nos linchamentos se faz presente a dimensão mais oculta do nosso imaginário, sobretudo nas formas elaboradas e cruéis de execução das vítimas. A centralidade do corpo nesse imaginário explode nas ações de linchamento, quando pacíficos transeuntes, pacíficos vizinhos, devotados parentes e pais se envolvem na execução de alguém a quem, ás vezes, estão ligados por vínculos de sangue, às vezes o próprio fillho. E, sobretudo, quando se envolvem na mutilação, na castração e na queima da vítima ainda viva. A forma que entre nós assume a chamada justiça popular está muito distante do romantismo ingênuo que tem marcado tão fundo os estudos sobre a cultura popular em nosso país e o discurso abstrato e ineficaz sobre cidadania.

\section{A Banalidade do Mal e a questão da Diferença.}

Ao analisar os dados apresentados pelos mapas da violência é possível notar que uma categoria social é mais atingida pela violência do que outras. Estamos nos referindo aos jovens e os negros, são eles os sujeitos sociais mais vitimados pelos homicídios e mortes violentas no país. Relacionando estas categorias com os crimes de linchamento é percebido que o maior número de vítimas deste tipo de "justiçamento" coletivo são jovens negros. Para compreender esta situação é importante analisar a questão da diferença na sociedade brasileira e como estas diferenciações, que transcendem as dimensões econômicas, são elementos importantes na banalização da violência sobre certos sujeitos e corpos. Este processo pode ser definido como uma forma de desumanização, possibilitando que pessoas "normais" ${ }^{1}$ e pacificas no seu diaa-dia exerçam uma violência sistemática.

\footnotetext{
${ }^{1}$ Quando nos referimos a "pessoas normais" estamos falando do fato de que sujeitos sociais pacíficos, como a dona de casa ou um trabalho qualquer, ser capaz de sair deste âmbito para exercer violência física sobre outro ser humano.
} 
De acordo com Hannah Arendt, em meio aos processos fundamentais de interação a atividade do pensar, poderia permitir ao sujeito ir um pouco além dos problemas mais comuns de decidibilidade no mundo, funcionando como um mecanismo de garantia da ética nos períodos de crise e em ocasiões em que se decide e age de maneira coerente exatamente quando se descumpre o convencionado socialmente. A autora, em sua obra $A$ Vida do Espírito, aponta como o não pensar evita o julgar e bloqueia a capacidade que temos de dizer "isto está certo" ou "isto está errado". O pensamento não seria uma prerrogativa de poucos, mas uma faculdade sempre presente em todos, e a inabilidade para pensar não seria uma imperfeição daqueles muitos a quem se falta Inteligência, mas uma possibilidade sempre presente nos indivíduos. A competência para agir conscientemente estaria intimamente ligada à atividade do pensar. Aqueles que não refletem teriam uma relação inadequada com o mundo, porque não conseguiriam se eximir da ação de cometer o mal, pois mesmo nestes casos ainda haveria liberdade da decisão de ação. Não pensar seria negar a si a responsabilidade pelos seus atos, e é justamente quando não refletimos sobre o mal que podemos realizá-lo, quando anestesiamos a criticidade. Se há algo no pensamento que possa impedir os homens de fazer o mal, esse algo seria provavelmente, alguma propriedade inerente à própria atividade de pensar.

Agora quem decidirá acerca do belo e do feio é algo mais do que o gosto, mas questão "moral" do certo e do errado não é para ser decidida nem pelo gosto nem pelo juízo, mas unicamente pela razão. (ARENDT, 2000).

De acordo com Kant o juízo não é a razão prática, a razão prática raciocina e diz-me o que fazer e o que não fazer. O juízo, pelo contrário, brota de um prazer meramente contemplativo, que nada tem a ver com a prática. Seria necessário "alargar o espírito" para ampliar a faculdade de Julgar. O alargamento do espírito é realizado através da comparação dos nossos juízos com outros juízos não tanto efetivos, mas antes possíveis, e por nos pormos no lugar de qualquer outro homem. O pensamento crítico só seria possível nos casos em que os pontos de vista de todos os outros estão abertos ao exame. Por isso, o pensamento crítico embora seja ainda uma tarefa solitária, significa pensar por si mesmo, que é a máxima de uma razão que nunca é passiva. Ser dado a tal passividade chama-se preconceito, e o esclarecimento é antes de tudo a libertação do preconceito. (ARENDT, 2000).

Para Hannah Arendt a falta do exercício de pensamento levaria a uma falta de profundidade. Essa falta de profundidade seria causada pelo juízo ser baseado no gosto e no preconceito, e não de acordo com uma razão prática. Fazendo com que as pessoas analisassem os fatos históricos, a política e as relações sociais de maneira superficial e irreflexiva, mas não irracional. E quanto maior é a falta de profundidade, maior será a suscetibilidade ao cometimento do mal. No entanto seria um tipo específico de mal, o mal banal que nada mais é que uma ação extrema que não possui nem profundidade e nem dimensão demoníaca. Não apresentando esta dimensão demoníaca qualquer pessoa, seja o trabalhador honesto, o cristão mais fiel, ou o maior criminoso, é capaz de cometê-lo, pois estaria agindo irreflexivamente, "sem pensar". Para a autora existem sistemas que banalizam o mal, multiplicando nas sociedades de massa a falta de profundidade e os fenômenos de superfície. Em paralelo com esta teoria, relaciono a atividade de irreflexão as atuais formas de resoluções de conflitos, extralegais. Sejam os grupos de extermínio, as chacinas, os linchamentos, os genocídios. De forma que os homens que praticam esses crimes, não são pessoas más por natureza, por 
tentação ou por vontade, e nem tenham sinais firmes de convicções ideológicas, nem tampouco irracionalidade, mas sim irreflexão. A irracionalidade seria a falta de capacidade de pensar, no entanto a atividade de pensar é inerente a toda a humanidade. Não pensar, não seria um ato irracional, mas irreflexivo. É de acordo com esta ideia que os casos de Justiçamentos não são considerados neste trabalho como movimentos irracionais, mas irreflexivos. Eles ocorrem por meio de movimentos de superfície que desumanizam determinadas categorias sociais consideradas como "corrosivas" para o bem estar da sociedade, e por conta disso seriam mais facilmente vitimizadas como maneira de "limpeza social".

Ao analisar os linchamentos por uma perspectiva dos processos de desumanização de outros seres humanos, é necessário problematizar como, por questões diversas, um sujeito social é visto como um não sujeito que pode, por este motivo, ser vítima de violência brutal, coletiva e pública, quais seriam os motivos que legitimam socialmente para os linchadores e para muitas pessoas estes atos brutais de violência que são vistos e entendidos como atos de justiça? Seria possível interpretar estas ações como sendo impulsionada por aspectos emocionais, a tentativa de equilibrar a fragilização da vida cotidiana, pública, concentrando suas insatisfações no ódio personalizado. Nesses crimes é essencial que não se trate mais a vítima como semelhante, pessoa que pensa, chora, ama, sofre, mas sim proceder a uma desumanização deste outro que agora passa a ser entendido enquanto um "elemento", "bandido", "marginal", perdendo a categoria de pessoa e cidadão com direitos. O essencial é que deixe de ser um ser humano, um indivíduo e que se torne uma categoria. Esse comportamento aponta para o distanciamento do Justiçador em relação à vítima. E este distanciamento é causado pela superficialidade do agente que não concebe a perplexidade do mal que comete. Hannah Arendt chama este distanciamento de "mediocridade transparente". A violência cometida pelos linchadores acontece pela falta de poder de participação na vida cotidiana, seja pela perda de segurança, falta de acesso à justiça, seja pelo rompimento de determinadas ralações morais. Para a autora, a violência é o oposto de poder, portanto a partir do momento em que a sociedade considera que as instituições não são mais capazes de responder os desejos da comunidade, existe um rompimento de um consenso quanto a um curso comum de ação (regras da justiça legal, direitos fundamentais), ou seja, a perda de poder. O poder seria a capacidade de agir em consenso, poder e violência seriam termos opostos: a afirmação de um significa a ausência do outro. O decréscimo do poder pela carência da capacidade de agir em conjunto é um convite à violência.

Esse processo de "categorização" de "desumanização" é gerado por meio de diversos incômodos sociais sempre que a consciência coletiva se depara com contradições de organização da sociedade. As noções de desigualdade e diferença são concepções e situações próprias da sociedade de cujas transformações emergiram o novo sujeito social que é o indivíduo. As formações sociais anteriores a sociedade contemporânea tinham sua organização fundamentada em uma concepção mais organicista de sociedade, os sujeitos sociais tem sua identidade definida a partir da participação enquanto membro e parte de um todo social possuidora de uma identidade grupal ou coletiva, fosse à tribo, a comunidade, a casta, o estamento. Prevalecia aí o pertencimento sobre a individualidade apenas potencial e remota, dependentes de transformações e ruptura sociais e históricas. Com os olhos de hoje podemos ver nessas formas de agrupamento e de 
organização social diferenças e desigualdades, mas nosso olhar atual é em si mesmo anacrônico e não pode ser utilizado como parâmetro de analise haja visto que reclama elementos de tempos e formações sociais e históricas que não os conhecem. Da mesma forma assumir o ponto de vista popular de que a sociedade foi igualitária e socialmente uniforme algum dia e que, por um perverso desvio qualquer, tenha se afastado dessa premissa idílica, pressupõem um simplismo, que, pretensamente politizante, atribui a desigualdade e a diferença um caráter intrinsicamente mau e perverso do capitalismo.

Com frequência, nos esquecemos de que a sociedade capitalista foi precedida por desigualdades e diferenças muito mais acentuadas do que as que conhecemos. (MARTINS, 2014, p. 161- 162).

E que a sociedade contemporânea ainda não explicitou todas as suas contradições. É interessante notar como não nos interrogamos suficientemente por qual razão a sociedade capitalista, que é estruturalmente contratual e igualitária, não corroeu e/ou ao menos superou desigualdades e diferenças que foram típicas do antigo regime. Ao contrário, o sistema capitalista normalmente fortaleceu e deu novas funções as estruturas de desigualdade que são essenciais ao seu núcleo lógico que é a acumulação de riqueza e a acumulação de poder. Formas próprias de exploração do trabalho pré-capitalista e pré-moderno tornaram-se poderosas fontes de acumulação de capital e tornaram-se fatores de gestação de categorias sociais marginais e impotentes para reivindicar até mesmo o que é essencialmente próprio da sociedade capitalista. De acordo Martins, a sociedade contemporânea não só criou novas formas de desigualdade, como manteve, embora de forma parcial, reformuladas e adaptadas, desigualdades anteriores.
Transformou as diferenças em categorias substantivas e meios de discriminação, fazendo delas instrumentos de um sistema de desigualdades, mais do que de um sistema de identidades e de direitos. No horizonte dessa desigualdade estrutural firmou-se a legitimidade, oriunda do escravismo colonial, das diferenças sociais como diferenças hierarquizantes e não diferenças de identidade. A diferença tem sido tratada como uma deficiência e uma privação, em vez de ser tratada pelos próprios sujeitos como qualidade diferencial positiva e matriz de identidade e de recusa da igualdade meramente ideológica, anuladora das diferenças. $\mathrm{Na}$ sociedade moderna, a diferença, só tem sentido como diferença cidadã e nessa perspectiva só pode ser derivada da igualdade jurídica, portanto da igualdade de direitos. (MARTINS, 2014, p.162).

Para compreender como as desigualdades sociais estão relacionadas aos processos de desumanização e violência é necessário diferenciar a igualdade jurídica da igualdade social. As sociedades modernas são marcadas por uma forma de igualdade que é juridicamente delimitada, estamos nos referindo aqui aos processos de construção dos Estados de direito, em suma, é a igualdade de direitos de todos os cidadãos pertencentes a um Estado nacional e diz respeito ao plano forma dos direitos, quando ultrapassamos este plano e nos voltamos para a dimensão social da vida coletiva, esta igualdade de direito encontra-se ameaçada pela realidade desigualdade do sistema econômico, esta desigualdade de condições econômicas resulta em desigualdades sociais mais amplas inclusive, mas não unicamente, no acesso à justiça e ao direitos.

A igualdade é uma construção que se dá nos embates sociais, produto e expressão da superação dos bloqueios a que a igualdade se confirme. A construção da igualdade se dá num campo de possibilidades e de limitações. É 


\section{O JUSTIÇAMENTO COLETIVO E A VIOLAÇÃO DOS DIREITOS HUMANOS NO ESTADO DEMOCRÁTICO DE DIREITOS}

evidente que não basta à lei dizer que somos iguais (MARTINS, 2014, p. 163).

No Brasil, a igualdade social e de direitos foi politicamente proposta, justamente pelos beneficiários da desigualdade; proposta, portanto, como igualdade limitada e condicional. Se a igualdade é uma construção social e política, a diferença na igualdade também o é. As diferenças de acesso que hoje geram a destituição da possibilidade de inserção na modernidade social, de determinadas categorias como os marginalizados, pobres, negros, entre outros, é resultante das iniquidades sociais herdadas da sociedade colonial. O que dificulta a aceitação de uma sociedade na sua universalidade, refreando uma consciência social que pense a redução de determinadas discriminações.

A identidade não se propõe no plano do mero querer e da mera subjetividade e sim no plano da circunstância e do vivencial, essa identidade é reduzida no seu alcance histórico pelas deformações ideológicas que decorrem das mediações que separam aquilo que o indivíduo quer e pensa que é daquilo que o indivíduo é sociológica e historicamente (MARTINS, 2014, p. 167).

No caso do negro não estamos em face de uma necessidade propriamente radical, que implique mudanças sociais profundas e abrangentes. Estamos em face de uma carência de pleno exercício de direitos, decorrente de uma história social de privações que estruturalmente tem alcançado, e alcançam negros e brancos, ainda que em desiguais proporções. As formas elementares e superficiais de manifestação das diferenças são, muitas vezes, objeto de manipulação política, manipulação que, contudo, não tem nenhum alcance histórico, a não ser o alcance circunstancial de pequena duração que pode decorrer da consciência cotidiana dos envolvidos (MARTINS, 2014, p.
168 - 169). No Brasil existe uma enorme carência de garantia de direitos fundamentais, como a vida, saúde, educação, segurança e de acesso ao sistema oficial de Justiça. Em especial o acesso da comunidade pobre onde boa parte é negra, pois existem barreiras econômicas de acesso ao Judiciário devido aos altos custos de litigação judicial. E apenas uma parte dos conflitos é administrada pela Justiça Legal, pois as causas de pequeno valor apresentam uma litigação financeiramente desvantajosa e não são absorvidas pelo sistema. Assim os conflitos sociais não canalizados por vias formais tendem a ser absorvidos por sistemas particulares de resolução de conflitos, dando espaço à violência ilegal e à supressão do oponente. Em meio a este contexto o Justiçamento Coletivo passa a ser uma resolução de conflito legítima não só no âmbito da Justiça Popular como na Justiça Legal, pois não é registrado como crime. É importante compreender, no entanto, que tanto os que cometem Linchamentos como as Vítimas, sofrem de dificuldade de acesso á Justiça e acabam por serem inseridos em lógicas de convivências sociais desiguais, de pobreza, criminalizadoras, racistas, e de desumanização. O que contribui ainda mais para que determinadas categorias, como a negra, sejam muito mais vitimizadas pela falta de acesso a seus direitos, a dignidade, a defesa e a Vida.

\section{Considerações Finais}

Os direitos fundamentais disponíveis aos cidadãos devem ser observados, respeitados e preservados, mesmo que em situações de aparente conflito. Para que o cidadão apresente seus direitos efetivamente protegidos, é imprescindível que o Estado, através de seus representantes eleitos pelo povo, atenda aos fundamentos do Estado Democrático de Direito. Isso só ocorre quando os direitos 
básicos à educação, saúde, trabalho, dentre outros direitos sociais, forem levados a efeito, além de ser oportunizado também um ambiente sadio e ecologicamente equilibrados. Mas como foi visto neste trabalho, a sociedade civil, e especialmente, a comunidade das periferias, apresentam uma enorme dificuldade de acesso a seus direitos, como consequência da dificuldade de acesso ao sistema legal de Justiça. A periferia aparece como uma geografia a parte, onde a distância, a diferenciação da paisagem e a diferença social constituem limites não só de fato, mas de direito, à ação da polícia e do Judiciário nesses lugares distantes. Existe, portanto certa aceitação da incapacidade de o poder público oferecer segurança nos bairros da periferia e em zonas periféricas. A falta de policiamento não é vista como irresponsabilidade de uma política pública de segurança e justiça ineficaz e ultrapassada, que deveria ser exercida igualmente em todos os lugares.

Além disso, o Judiciário é enxergado de maneira dualista, de um lado a Justiça Pública é vista como o meio mais adequado para resolução de conflitos criminais. Num plano ideal a justiça oficial é sempre positivamente valorada. Entretanto, quando se fala da prática, fala-se também da morosidade, dos altos custos dos serviços de advocacia, dos recortes de classe nas sentenças judiciais. A justiça penal no Brasil enquadra os crimes e distribui punições de maneira seletiva. A estratégia de regulação da vida por meio do crime e da pena é quase onipresente, seria uma politização do crime, e essa politização apresenta várias facetas como; o reforço de relações hierárquicas segue uma dinâmica de desigualdade de classe, raça e gênero; com o populismo da classe política e sua inércia na não execução de reformas efetivas; com o mercado lucrativo da segurança; com a manipulação fácil de uma sociedade acuada. Mas em longo prazo seus efeitos mais perversos são também a destruição da confiança da população em relação às instituições e a asfixia do debate democrático. Os conflitos criminais vividos pelas pessoas que moram na periferia da grande metrópole e nas zonas rurais estão na fronteira da ação do Judiciário, são espaços que o Estado não se interessa em ocupar. Essas comunidades acabam por cuidar de sua própria segurança, e às vezes de sua própria justiça. Embora, manifeste-se no discurso de um desejo de inclusão desses conflitos na esfera estatal e pública.

Os casos de linchamento são consequência de conflitos que não encontraram uma via de canalização nas instâncias oficiais. Mas foram absorvidos pela mobilização da comunidade diante do medo e do sentimento de injustiça coletivos. A revolta mobiliza a rede de relações das comunidades para a ação de justiça popular. E esses Justiçamentos são vistos como uma produção efetiva da justiça, em que o coletivo recupera uma correlação de forças que havia sido violada, instaurando um novo equilíbrio no lugar onde havia a tensão entre os Justiçadores e suas vítimas, que são normalmente a categoria do bandido, do estuprador, do vagabundo, e a categoria das pessoas negras, que são vítimas de uma discriminação histórica e acabam sendo reconhecidas como o "inimigo comum". Aos olhos dos linchadores, a justiça popular praticada na forma do linchamento concorre com a justiça oficial e apresenta sua vantagem, na medida em que interfere no conflito com os "bandidos", "vagabundos", e promove a pacificação do lugar aonde ocorre a ação. E o que sobressai são relações políticas de outra natureza, que ancoram e legitimam as ações da justiça popular.

Essa tensão política de inclusão/exclusão faz com que se leia os linchamentos não apenas como resposta aos conflitos interpessoais, mas 


\section{O JUSTIÇAMENTO COLETIVO E A VIOLAÇÃO DOS DIREITOS HUMANOS NO ESTADO DEMOCRÁTICO DE DIREITOS}

como expressão de próprio conflito social. O linchamento, além de um ritual de execução de justiça que repõe reciprocidades quebradas no nível local de sociabilidade, é uma expressão de ruptura com um estado de coisas, é uma forma de protesto social, contra o crime e o criminoso, mas também contra a polícia, a justiça, os políticos, que não fazem o que deveria ser feito segundo as expectativas daqueles que se revoltam ou apoiam a revolta. No entanto, os linchamentos são o reflexo de uma grave crise social. O Brasil é um dos países mais violentos do mundo, e é o país que mais lincha. A violência não se resume aos bandidos organizados e armados ou de esquadrões de policiais que decidiram tomar nas mãos as funções da sociedade, da justiça e da polícia. Mas setores da própria sociedade, facilmente dispostos a matar com as próprias mãos quando o móvito existe a oportunidade se apresenta. As ocorrências de ações coletivas de execução capital, neste país, levadas a efeito por pessoas "iguais a nós", como se diz, deveria dar o que pensar.

Mesmo os não inocentes têm direito à justiça institucional, não por que com isso se esteja concedendo a eles algum privilégio. Não cabe, pois, a vingança ou a punição exemplar, como parece ocorrer nesses massacres, formas primitivas de justiçamento, dos tempos em que qualquer crime era considerado assunto privado. Essa modalidade de crime era monopólio do chamado poder pessoal, sobretudo dos potentados rurais do tempo da escravidão. Terminada a escravidão, essa desigualdade profunda de direitos, que sustentava a violência intrínseca do tipo de sociedade que herdamos, longe de acabar, se disseminou e se fortaleceu. O que era violência privada se disseminou. A ditadura militar implantada em 1964 colocou a ordem diante do direito, o arbítrio de alguns adiante da lei de todos, tolerou os esquadrões da morte no âmbito da criminalidade comum e não titubeou em convocar os próprios delinquentes desses grupos para a prática da tortura e até do assassinato de presos políticos. O retorno do estado democrático de direito não se expandiu o acesso à justiça e ao direito. Muitos acreditaram que bastava novo governo, uma constituição democrática, que a ordem se reestabeleceria automaticamente. $\mathrm{E}$ não foi $\mathrm{o}$ que aconteceu, pois não se levou em conta que a desordem do Estado ditatorial viabilizaria o revigoramento e a difusão da cultura e do poder pessoal, da vendeta, do arbítrio, do menosprezo pela pessoa e pelo corpo do outro, agora colocados nas mãos até de membros das forças policiais. A completa banalização da vida e do mal, em que determinadas categorias sociais se encontram em um espaço de esquecimento do qual nada e nem ninguém pode retirá-las. A desordem regulando a ordem, a morte regulando a vida.

As revoltas contra a condição de periferia política não propõe a revolução das relações de poder da sociedade, pois, não há um desejo de destruição das instituições; ao contrário, o que se quer é expandir o Judiciário e a Polícia. Assim como o alvo da ação são aqueles que imediatamente amaçam a segurança local, como é comum ocorrer em sociedades em que as relações de dominação não são produzidas face-a-face entre poderosos e subalternos, mas são atravessadas por uma série de medições e reproduções; desta forma, nos motins reage-se contra aquele que representa na situação concreta a exploração e a violação do direito à segurança que os amotinados acreditam deter.

Embora, por essas razões, nitidamente associados a movimentos conservadores, os processos aqui estudados indicam um questionamento da posição que ocupam esses habitantes da periferia no sistema de poder desta sociedade. Da profundidade desse questionamento 


\section{O JUSTIÇAMENTO COLETIVO E A VIOLAÇÃO DOS DIREITOS HUMANOS NO ESTADO DEMOCRÁTICO DE DIREITOS}

depende a manutenção de uma política de segurança pública e de justiça baseada na atual divisão social do trabalho e da distribuição de justiça, ou uma modificação das relações de poder que permita a incorporação de uma diversidade maior de interesses no exercício do poder público. O processo de racionalização da atividade judicial, com a constituição de um corpo específico de funcionários, com alta codificação dos procedimentos, a construção de um campo de conhecimento e poder o seu limite nas revoltas populares que caracterizam a ocorrência dos linchamentos. Estes expressam o estranhamento e a frustração das expectativas daqueles que deles tomam parte, ao mesmo tempo em que se ancoram a reforçam um contexto mental de descrédito nas instituições oficiais, contexto em que operam dispositivos costumeiros de justiça e canalização de conflitos. Os linchamentos são expressão de um conflito de interesses que ganha uma dimensão política na medida em que questionam a desigualdade de acesso às instituições públicas, à participação nas políticas públicas, à desigualdade enfim no exercício da cidadania e da própria condição humana. Diante desse estado de coisas, é possível evitar o mal a partir do pensamento? A atividade do pensar é capaz de definir um agir ético? Para Hannah Arendt, face de um mundo fora dos eixos, resistir seria um dever que ela expressa sob a forma de um imperativo tomado de empréstimo a Karl Jaspers: É importante estar plenamente presente. Para agir de forma coerente com o humano e com o bem comum, mesmo quando o estado de coisas se tornar intolerável, a atividade do pensar é capaz de tornar o homem plenamente presente, no domínio do público e do privado. Religando a atividade de refletir, imaginar e querer à ação.

\section{Referências Bibliográficas}

ARENDT, Hannah. A Vida do Espírito. Querer. Porto Alegre: Instituto Piaget, 1978.

AREDNT, Hannah. Sobre a Violência. Rio de Janeiro: Relume Dumará, 1994.

DENAMY, Sylvie. O Cuidado com o Mundo: Diálogo entre Hannah Arednt e alguns de seus contemporâneos. Belo Horizonte: Editora UFMG, 2004.

MARTINS, José de Souza. Uma Sociologia da Vida Cotidiana. São Paulo: Contexto, 2014.

MARTINS, José de Souza. Linchamentos: A Justiça Popular no Brasil. São Paulo: Contexto, 2015.

SINHORETTO, Jacqueline. A Justiça Perto do Povo: Reforma e Gestão de Conflitos. São Paulo: Alameda, 2011.

SINHORETTO, Jacqueline. Os Justiçadores e sua Justiça: Linchamentos, Costume e Conflitos. São Paulo: IBCCRIM, 2002. 